\title{
Implication of OTX2 in Pigment Epithelium Determination and Neural Retina Differentiation
}

\author{
Paola Bovolenta, ${ }^{1,2}$ Antonello Mallamaci, ${ }^{2}$ Paola Briata,, ${ }^{4}$ Giorgio Corte, ${ }^{4,5}$ and Edoardo Boncinelli ${ }^{2,3}$ \\ ${ }^{1}$ Department of Neurobiologia del Desarrollo, Instituto Cajal, Consejo Superior de Investigaciones Científicas, Madrid \\ 28002, Spain, 2Departimento di Ricerca Biologica e Tecnologica, Istituto Scientifico H. S. Raffaele, 20132 Milan, Italy, \\ ${ }^{3}$ Centro Infrastrutture Cellulari, Consiglio Nazionale delle Ricerche, 20129 Milan, Italy, ${ }^{4}$ Centro di Biotecnologie Avanzate, \\ 16132 Genoa, Italy, and 5/stituto di Chimica Biologica, Università di Genova, Genoa, Italy
}

\begin{abstract}
The expression pattern of Otx2, a homeobox-containing gene, was analyzed from the beginning of eye morphogenesis until neural retina differentiation in chick embryos. Early on, Otx2 expression was diffuse throughout the optic vesicles but became restricted to their dorsal part when the vesicles contacted the surface ectoderm. As the optic cup forms, Otx2 was expressed only in the outer layer, which gives rise to the pigment epithelium. This early Otx2 expression pattern was complementary to that of PAX2, which localizes to the ventral half of the developing eye and optic stalk. Otx2 expression was always observed in the pigment epithelium at all stages analyzed but was extended to scattered cells located in the central portion of the neural retina around stage 22 . The number of cells expressing Otx2 transcripts increased with time, following a central to
\end{abstract}

peripheral gradient. Bromodeoxyuridine labeling in combination with immunohistochemistry with anti-OTX2 antiserum and different cell-specific markers were used to determine that OTX2-positive cells are postmitotic neuroblasts undergoing differentiation into several, if not all, of the distinct cell types present in the chick retina. These data indicate that Otx2 might have a double role in eye development. First, it might be necessary for the early specification and subsequent functioning of the pigment epithelium. Later, OTX2 expression might be involved in retina neurogenesis, defining a differentiation feature common to the distinct retinal cell classes.

Key words: chick; PAX2; pigment epithelium; optic cup; neurogenesis; postmitotic neuroblast; retinal ganglion cell
Eye development begins with the lateral protrusion of the forebrain to form the optic vesicles. Thereafter, the surface ectoderm overlying the vesicles gives rise to the lens placode, which induces the formation of the optic cup, from which the optic stalk, pigment epithelium, and neural retina all arise. Cells in the retinal neuroepithelium will then divide to generate the different neuron and glia cell types that compose the vertebrate retina (Saha et al., 1992). Lineage analysis has shown that retinal progenitor cells are multipotential and that phenotypic selection may be the result of cell interactions with microenvironmental factors (Lillien, 1994).

Transcription factors in general and homeobox containing genes in particular are fundamental for the genetic control of different basic developmental processes (Gehring et al., 1994;

Received Jan. 24, 1997; revised March 13, 1997; accepted March 21, 1997.

This work was initiated while P.B. was holding European Community Contract BI02-CT-94-6293 in the laboratory of E.B. This study was supported by Spanish Ministry of Education Grants PB94-0102 (DGICYT) to P.B. and by grants from European Community Biotech and Telethon-Italia Programs to E.B. and the Italian Association for Cancer Research to E.B. and G.C. The mAb anti-Islet-1, developed by Prof. T. M. Jessell, was obtained by the Developmental Studies Hybridoma Bank maintained by the Department of Pharmacology and Molecular Sciences, Johns Hopkins University, School of Medicine (Baltimore, MD), and the Department of Biological Sciences, University of Iowa (Iowa City, IA), under contract N01-HD-2 3144 from the National Institute of Child Health and Human Development. We are grateful to Drs. Steve McLoon, Jane Dodd, Enrique de la Rosa, and Gregory Dressler for their kind gifts of the RA4, 3A10, 3CB2, and anti-PAX2 antibodies, respectively. We are indebted to Juan Ramon Martinez-Morales and Dr. Alfredo Rodriguez-Tebar for their many helpful suggestions and also to Drs. Julio A. Barbas, Angela Nieto, and Miguel Torres for critical reading of this manuscript. The expert technical assistance of Concha Bailon with confocal microscopy is also gratefully acknowledged.

Correspondence should be addressed to Dr. Paola Bovolenta, Instituto Cajal, Consejo Superior de Investigaciones Científicas, Doctor Arce 37, Madrid 28002, Spain.

Copyright (C) 1997 Society for Neuroscience $0270-6474 / 97 / 174243-10 \$ 05.00 / 0$
Lawrence and Morata, 1994). Therefore, the study of these genes might be crucial to understand the steps leading to the formation of a well organized and functional eye. Otx2 together with other homeobox containing genes have been detected at early and later stages of eye and retinal development (Saha et al., 1992; Halder et al., 1995). Otx2, originally isolated and characterized in mouse (Simeone et al., 1992, 1993), is one of two homologs of orthodenticle, a regulatory gene controlling the determination of specific head segments in Drosophila (Finkelstein and Perrimon, 1991). In early vertebrate embryos, Otx2 has a widespread expression in the epiblast but becomes progressively restricted to the anterior portion of the embryo at the headfold stages. Later in development, Otx2 expression covers most of the forebrain and midbrain neuroepithelium, including the eye domain, with a sharp posterior boundary at the midbrain-hindbrain junction (Boncinelli and Mallamaci, 1995). This expression pattern and the strong evolutionary conservation of this gene suggested a pivotal role for its protein in the specification of anterior neural structures. This hypothesis was confirmed by the analysis of three different Otx $2^{-1-}$ mice, because homozygotes showed defects in gastrulation and deletion of rostral brain (Acampora et al., 1995; Matsuo et al., 1995; Ang et al., 1996). Furthermore, Matsuo et al. (1995) reported the presence of severe eye defects, such as microphtalmia, hyperplastic retina and pigment epithelium, and lack of lens, cornea, and iris, in the heterozygotes, suggesting that Otx2 might be directly involved in the control of eye development.

To address more closely the role of $0 t x 2$ in eye formation, we have analyzed in detail Otx2 expression in the developing chick eye. Here, we show that Otx2 mRNA becomes progressively restricted to the dorsal region of the optic vesicles. Later, when 
the optic cup is formed, Otx2 is confined to the outer layer of the optic cup (the prospective pigment epithelium), with a sharp boundary at the optic stalk, where Pax2 is expressed (Nornes et al., 1990; Macdonald et al., 1995; Torres et al., 1996). Thereafter, Otx2 also seems to be expressed in the neural retina associated with postmitotic neuroblasts that are differentiating into different cell types, supporting the idea that the distinct cell classes present in the neural retina share common maturation characteristics.

\section{MATERIALS AND METHODS}

Chick embryos. Fertilized eggs from White Leghorn hens were obtained from local suppliers and were incubated at $38.5^{\circ} \mathrm{C}$ in an atmosphere of $70 \%$ humidity. Embryos were staged according to the method of Hamburger and Hamilton (1951).

In situ hybridization. The Otx 2 cDNA in pBluescript $\mathrm{SK}^{-}$was linearized and transcribed to generate digoxigenin-labeled antisense and sense probes, as described elsewhere (Bally-Cuif et al., 1995). Whole-mount in situ hybridization was performed according to the method of Nieto et al. (1996) on embryos staged between Hamburger and Hamilton stage 9 (HH9) and HH16. After hybridization, embryos were photographed using a stereomicroscope (Leica, Nussloch, Germany), cryoprotected in a saccharose solution (see below) and cryostat sectioned along the longitudinal plane of the embryo at a $35 \mu \mathrm{m}$ thickness. Sections were collected on gelatin-coated slides, air dried, washed in PBS, and mounted with PBS and glycerol.

Hybridizations of chick retinal sections were carried out following the protocol of Schaeren-Wiemers and Gerfin-Moser (1993), with the following modifications. Embryos were fixed in $4 \%$ paraformaldehyde in $0.1 \mathrm{M}$ phosphate buffer (PB), $\mathrm{pH} 7.3$, at $4^{\circ} \mathrm{C}$ between $3 \mathrm{hr}$ and overnight, depending on the size of the embryos, and then cryoprotected by immersion in $30 \%$ sucrose solution in PB. The tissue was embedded in O.C.T. compound (Tissue-Tek; Miles Inc., Elkhart, IN) and sectioned at 12-16 $\mu \mathrm{m}$ with a cryostat. Sections were mounted on 2\% 3-aminopropyltriethoxy-silane-coated slides and air dried. After permeabilization with $1 \%$ Triton X-100 in PBS for 30 min at room temperature, sections were fixed again in $4 \%$ paraformaldehyde in $\mathrm{PB}$ and acetylated with $0.3 \%$ acetic anhydride. Sections were then prehybridized for $2 \mathrm{hr}$ at $60^{\circ} \mathrm{C}$, incubated with probes for $16 \mathrm{hr}$ at $60^{\circ} \mathrm{C}$, and washed at the same temperature. Sections were analyzed and photographed using an Axiophot microscope (Zeiss, Oberkochen, Germany).

In ovo Bromodeoxyuridine injections. At embryonic day 4 (E4) and E5, chick embryos received a single injection of a saline solution containing $50-100 \mu \mathrm{g}$ of bromodeoxyuridine (BrdU; Boehringer Mannheim, Indianapolis, IN), a thymidine analog, into a vein of the chorioallantoic membrane. Eggs were sealed and returned to the incubator for 3-12 hr. After each postinjection time, embryos were fixed, and BrdU was localized using anti-BrdU-specific antibodies, as detailed below.

Antibodies. Polyclonal antiserum against the mouse OTX2 protein, produced in a Baculovirus system, was raised as described previously (Mallamaci et al., 1996). Briefly, HY-CR rabbits (Charles River, Lecco, Italy) were immunized with subcutaneous injections at $15 \mathrm{~d}$ intervals with $100 \mu \mathrm{g}$ of the purified OTX2 recombinant protein in Freund's adjuvant (Sigma, St. Louis, MO). Seven days after the fourth injection, the rabbit was bled, and the serum was tested by an ELISA, using plates coated with purified recombinant OTX2 and alkaline phosphatase-goat anti-rabbit $\mathrm{IgG}$ antiserum (Sigma). Immunoglobulins directed against nonspecific mouse antigens were removed by adsorption with a mouse liver total lysate immobilized on cyanogen bromide-activated Sepharose 4B (Pharmacia). The antiserum was used at a 1:1000 dilution.

The antiserum directed against the mouse PAX2 protein was used at a 1:800 dilution (Puschel et al., 1992). The RA4 monoclonal antibody $(\mathrm{mAb})$, which specifically recognizes premigratory and migrating retinal ganglion cells (RGCs) within the chick retina (McLoon and Barnes, 1989; Waid and McLoon, 1995), was used at a 1:1000 dilution of hybridoma culture supernatant. The $3 \mathrm{~A} 10 \mathrm{mAb}$, directed against a neurofilamentassociated antigen expressed by differentiating neurons (Furley et al., 1990), was used in a 1:5 dilution of hybridoma culture supernatant. mAb 40.2D6, directed against islet-1, used to identify mature RGCs (Austin et al., 1995), was obtained from the Developmental Studies Hybridoma Bank and was used in a 1:1000 dilution of ascitic fluid. The 3CB2 mAb was used, in a 1:500 dilution of ascitic fluid, to specifically identify Müller cells (Prada et al., 1995). The mAb against BrdU was purchased from Boehringer Mannheim and used at a 1:200 dilution.
Immunocytochemistry. Chick embryos were removed from the shell and washed in PBS, and the whole embryos or the heads, depending on the size of the embryos, were immersion fixed in $4 \%$ paraformaldehyde in $\mathrm{PB}$ overnight at $4{ }^{\circ} \mathrm{C}$. After washing in PBS, the tissue was equilibrated in a solution of $30 \%$ sucrose in PBS and embedded in OCT compound. Frontal cryostat sections of $12 \mu \mathrm{m}$ thickness were collected on gelatincoated slides and processed for immunohistochemistry as follows. Sections were blocked with $100 \mathrm{~mm}$ glycine in PBS for $30 \mathrm{~min}$, followed by 1 $\mathrm{hr}$ in PBS containing $0.1 \%$ Tween and $10 \%$ goat serum. Sections were then incubated overnight at $4^{\circ} \mathrm{C}$ with an appropriate dilution of different primary antibodies in PBS containing $0.1 \%$ Tween and $1 \%$ goat serum (PTG), alone or in conjunction with anti-OTX2 antiserum in the case of double staining. To detect BrdU incorporation, slides were pretreated with $2 \mathrm{~N} \mathrm{HCl}$ in $50 \mathrm{~mm} \mathrm{PBS}$ for $30 \mathrm{~min}$ at room temperature to denaturate DNA and neutralized with three washes of $0.1 \mathrm{~m}$ borate buffer, $\mathrm{pH} 8.5$. Sections were thereafter treated as described above and incubated with anti-BrdU antibodies. To localize primary antibodies, after three washes in PTG, sections were incubated at room temperature with goat antimouse IgG or goat anti-rabbit IgG conjugated to either Cy2, Cy3, or Cy5 (Amersham). Secondary antibodies were diluted 1:1000 in PTG. After rinsing in PTG, sections were mounted with PBS and glycerol and analyzed with a TCS 4D laser scanning confocal imaging system equipped with a krypton-argon ion laser (Leica). Confocal microscopy allowed an accurate analysis of immunostained cells and a precise quantification of double-stained cells when double labeling was performed.

\section{RESULTS}

\section{Otx2 expression at early stages of chick eye development}

The expression pattern of Otx2 was characterized by in situ hybridization at early stages of eye development. Between HH9 and HH16, Otx2 transcripts were detected in the anterior portion of the brain with a sharp posterior boundary at the midbrain-hindbrain junction, as described previously in the mouse and chick (Fig. 1) (Simeone et al., 1992; Bally-Cuif et al., 1995). The outpockets of the anterior neural tube, visible between stages HH9 and HH11 as the first sign of eye development, presented a diffuse expression of Otx2 (Fig. 1B,D), as observed in cryostat frontal sections of the stained embryos. However, a few hours later when the optic vesicles made close contact with the surface ectoderm (HH13), Otx2 expression disappeared from the distal edge of the optic vesicles and localized only to their dorsal portion (Fig. $1 F$ ). As the optic cup formed (HH16), Otx2 expression was segregated to the outer layer of the optic cup (Fig. $1 H$ ), from which the pigment epithelium derives. This expression ended abruptly at the junction with the optic stalk (Fig. $2 A, C$ ) on one side and at the iris-forming region on the other side (Fig. $1 H$ ). Thereafter, Otx2 expression, both of mRNA and protein, in the pigment epithelium was always observed at all developmental stages analyzed (Fig. 3).

Neuroepithelial cells of the prospective pigment epithelium are continuous and morphologically indistinguishable from those of the optic stalk. Nevertheless, Otx 2 expression seemed totally absent from the optic stalk. To determine whether Otx2 expression delimited the pigment epithelium domain, we compared its expression pattern by immunocytochemistry with that of Pax2, a paired box gene, expressed in the ventral half of the optic vesicles with a progressive restriction to the optic stalk (Nornes et al., 1990; Torres et al., 1996). In frontal cryostat sections of HH18 embryos, PAX2 was detected both in the inner and outer layers of the optic cup as well as in the optic stalk (Fig. 2B). In contrast, OTX2 was confined to the dorsal part of the prospective pigment epithelium with a sharp boundary at the junction with the optic stalk, where PAX2 expression began (Fig. 2A). One day later (HH24), when PAX2 expression is no longer present in the neural and pigment retina but is expressed in the developing optic nerve and chiasm, OTX2 was detected in the ventral pigment epithelium up to 

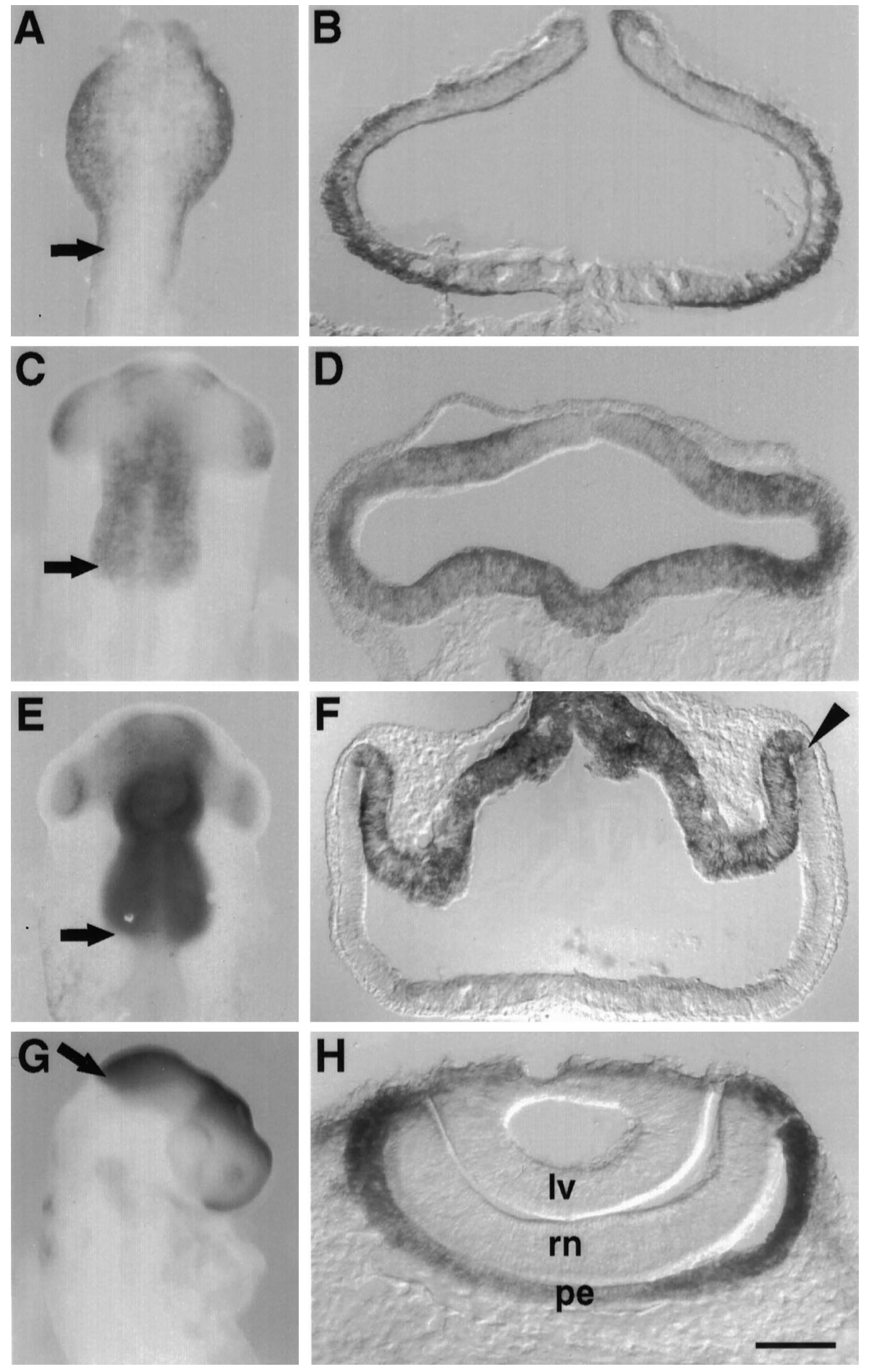

Figure 1. Early expression pattern of Otx2 in the developing chick eye. Chick embryos of stages HH9 $(A, B)$, HH11 $(C, D)$, HH13 $(E, F)$, and HH16 $(G, H)$, subjected to whole-mount in situ hybridization, presented a clear pattern of expression in the anterior portion of the neural tube with a sharp boundary between mesencephalon and rhomboencephalon (arrows in $A, C, E, G$ ). Frontal cryostat sections of the stained embryos show the distribution of Otx2 within the eye domain at each developmental stage. Note that Otx2 is diffuse throughout the optic vesicles at $\mathrm{HH} 9$ and $\mathrm{HH} 11$ $(B, D)$ but retracts to their dorsal portion at HH13 (arrowhead in F). Otx2 expression in the eye was limited to the prospective pigment epithelium at HH16 $(F)$. $l v$, Lens vesicle; $r n$, neural retina; $p e$, pigment epithelium. Scale bars: $A, C, E, 400 \mu \mathrm{m}$; $G, 500 \mu \mathrm{m} ; B, D, F, 40 \mu \mathrm{m} ; H, 20 \mu \mathrm{m}$. the junction with the optic nerve (Fig. 2C,D), suggesting that OTX2 and PAX2 expression might be mutually exclusive in this region.

At this stage OTX2 was also strongly expressed by all the cells that compose the developing ciliary bodies (Fig. 2C) and later in cells that compose the iris, as already reported in the mouse (Simeone et al., 1993). Furthermore, OTX2 was expressed in scattered cells of the neural retina, as detailed below.

\section{Expression pattern of Otx2 in the developing chick retina}

The close contact between the inner and the outer layers of the optic cup commences at around stage HH20. At this stage, Otx2
mRNA and protein were still expressed only in the prospective pigment epithelium (Fig. 3A,B). However, a few hours later (HH22), when neural retina differentiation begins (Prada et al., 1991), Otx2 products were detected in a few scattered cells of the central retina (Fig. 3C,D). The number of Otx2-positive cells, numerous in the mitotic region but sparse toward the vitreal surface, increased with development (Fig. $3 E, F$ ). Immunopositive cells also extended to the peripheral retina, following the reported gradients of differentiation (Khan, 1973; Prada et al., 1991). At E18 (HH44), chick retinal development is completed, and all cell types can be easily recognized by their precise location in the well 

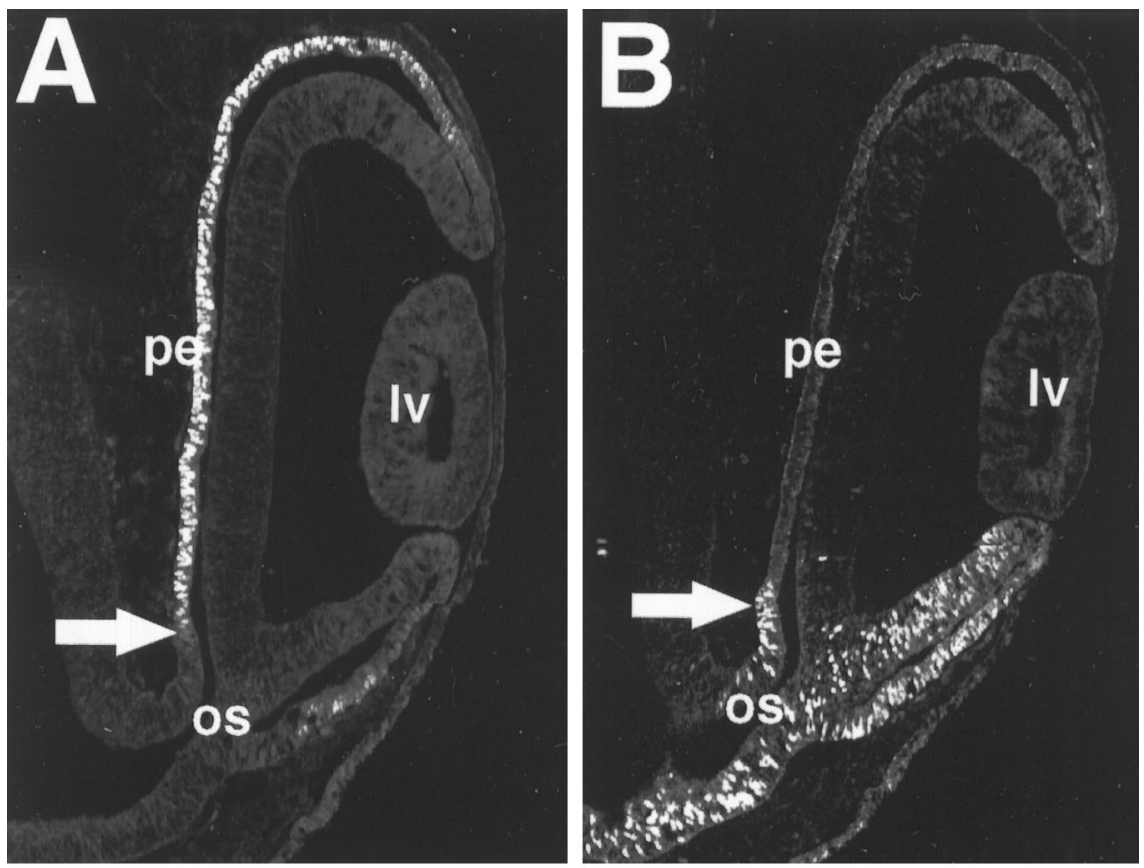

Figure 2. Comparison between OTX2 and PAX2 expression pattern in the eye. Confocal microscopic images of frontal cryostat sections through chick eyes at $\mathrm{HH} 18(A, B)$ and $\mathrm{HH} 24(C, D)$ immunostained with antiserum against $\mathrm{OTX} 2(A, C)$ or PAX2 $(B, D)$. Note how pigment and optic stalk epithelial cells are in close proximity $(A, B)$, but a sharp boundary (arrows in $A, B$ ) delimits Pax2 and Otx2 expression. OTX2 is expressed in the ventral pigment epithelium $(C)$ when PAX2 labels only the optic nerve $(D)$. $c b$, Ciliary bodies; $l v$, lens vesicle; le, lens; $n r$, neural retina; on, optic nerve; os, optic stalk; pe, pigment epithelium; $v$, ventral. Scale bar, $40 \mu \mathrm{m}$.
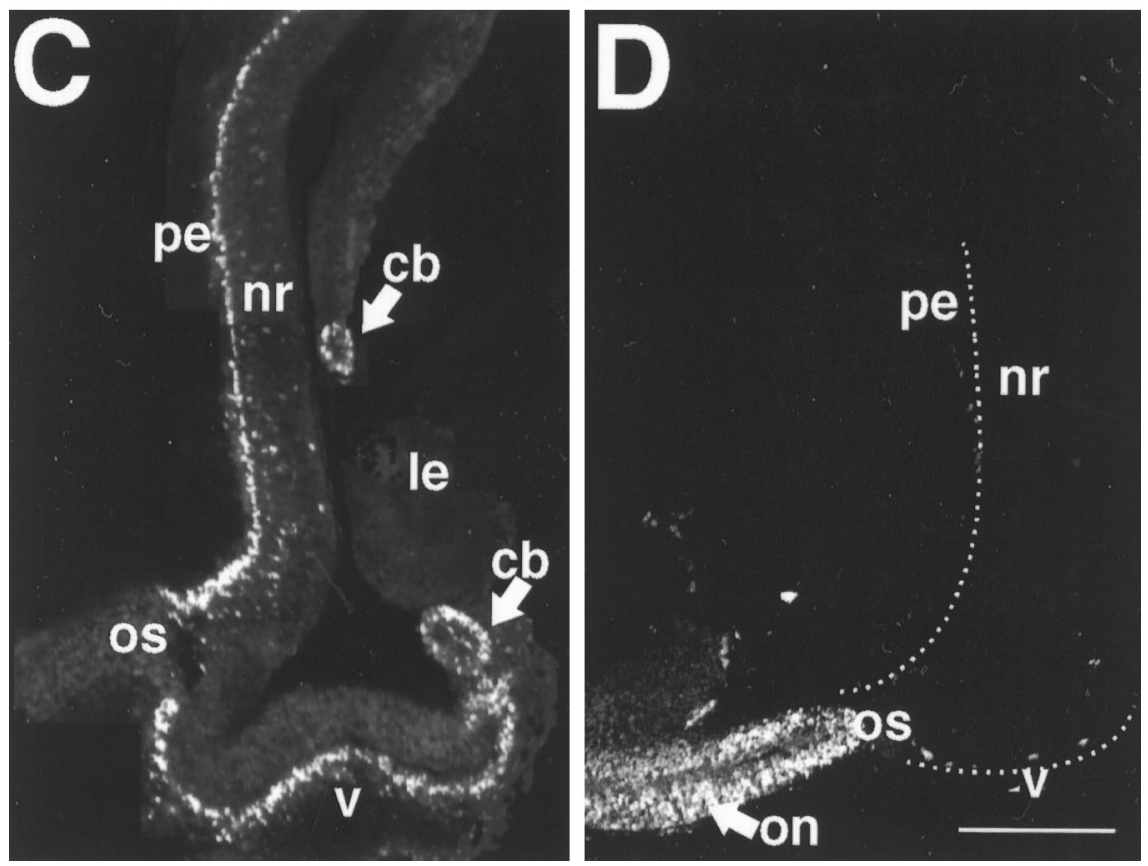

structured layers of the retina (Fig. 3G). At this stage, OTX2 was found in the nuclei of horizontal and photoreceptor cells and in a subpopulation of cells in the outer region of the inner nuclear layer (Fig. 3H). This layer is normally occupied by bipolar and Müller cells. Because OTX2-positive nuclei were scattered throughout the inner nuclear layer, they probably belonged to the latter cell type, as also suggested by double-labeling experiments performed with a Müller cell-specific marker (Fig. $5 F$; see below).

The expression pattern of $O t x 2$ in the developing mouse retina was similar to that in the chick, although somewhat delayed (data not shown). Chick and mouse retinas have a similar organization, but in rodents, retinal progenitor cell division and the subsequent cell type differentiation is protracted postnatally (Young, 1985), explaining the delayed progression of Otx2 expression. As in chick, adult mouse horizontal, photoreceptor, and possibly Müller cells expressed OTX2.

\section{OTX2 is expressed in postmitotic retinal neuroblasts}

Between E3 and E9 (HH20-HH35), Otx2 distribution in the retina was consistent with that expected for a gene involved in retinal neuroblast differentiation. Indeed, during this period, the majority of chick retina neuroepithelial cells replicate their DNA at the vitreal surface, undergo their last mitosis close to the pigment epithelium, and differentiate into one of the seven cell types that compose the vertebrate retina (Prada et al., 1991). Because of their position, it was possible that OTX2-positive nuclei belonged either to proliferating neuroepithelial cells or to postmitotic neuroblasts in the process of differentiation. To dis- 

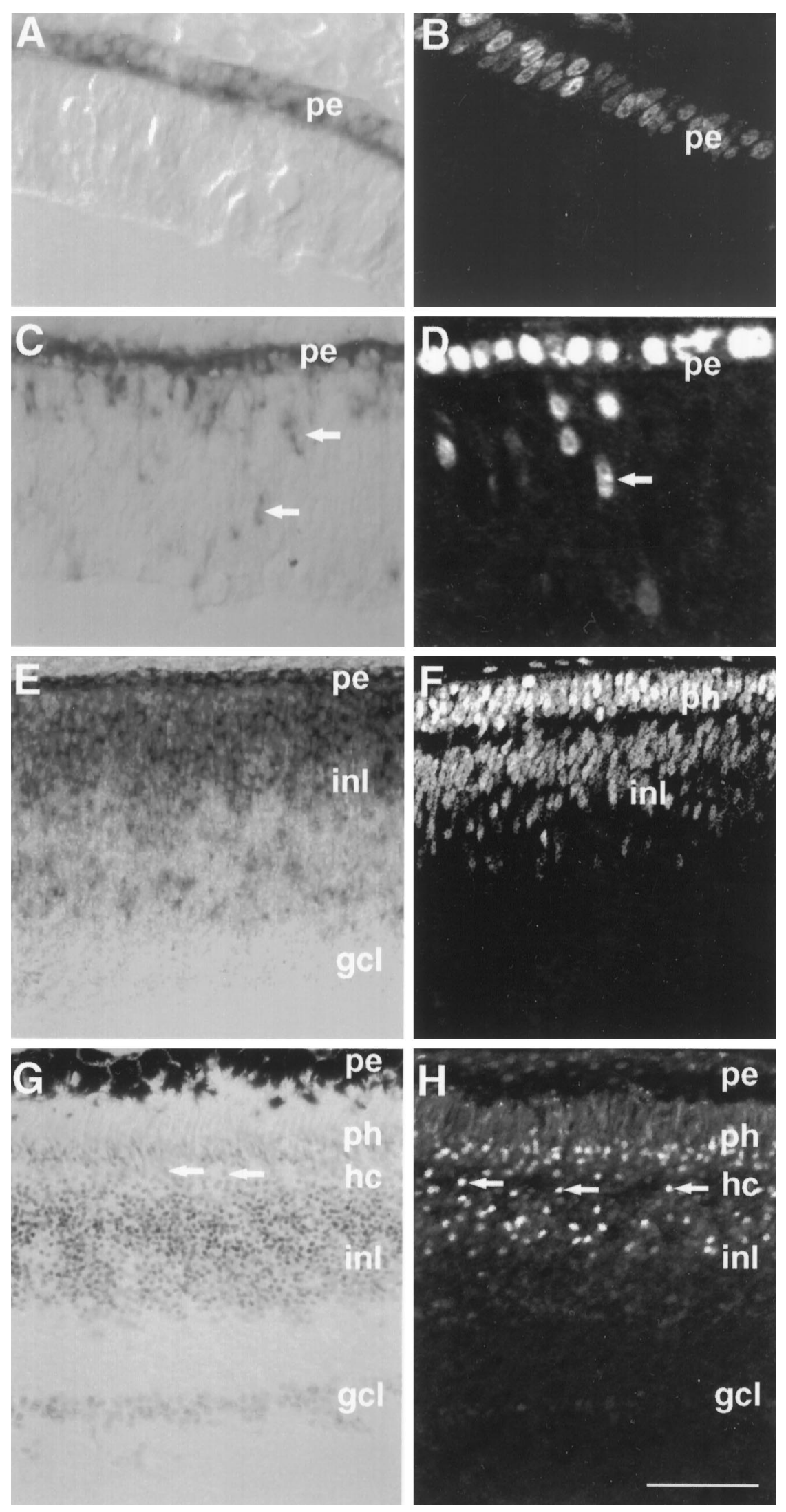

Figure 3. Otx2 mRNA and protein localization in the embryonic chick retina. Frontal cryostat sections of chick retinas hybridized with a digoxigenin-labeled probe $(A, C, E)$ or immunostained with antiserum against OTX2 $(B, D, F, H)$ at E3 $(A, B), \mathrm{E} 3.5(C, D), \mathrm{E} 9(E, F)$, and $\operatorname{E18}(G, H)$. Otx2 mRNA and protein were detected in a few scattered cells of the central retina (arrows in $C, D$ ). The number of Otx2-positive cells increased with development $(E, F)$. $G$, Cresyl violetstained section of a fully differentiated retina in where its layered structure is clearly visible. Note how the nuclei of horizontal cells (arrows in $G, H$ ) are OTX2 positive. $g c l$, Ganglion cell layer; $h c$, horizontal cells; inl, inner nuclear layer; $p e$, pigment epithelium; $p h$, photoreceptors. Scale bars: $A-D, 35 \mu \mathrm{m} ; E, F, 40 \mu \mathrm{m} ; G, H$, $60 \mu \mathrm{m}$. tinguish between the two possibilities, E4 and E5 (HH24-HH27) embryos were injected with BrdU and fixed after 3-12 hr. This length of time is the average duration of the $G_{2}$ to $M$ phase transition at different stages of chick retinal development (Waid and McLoon, 1995).

BrdU was localized in the outer two-thirds of the E4 retinal 

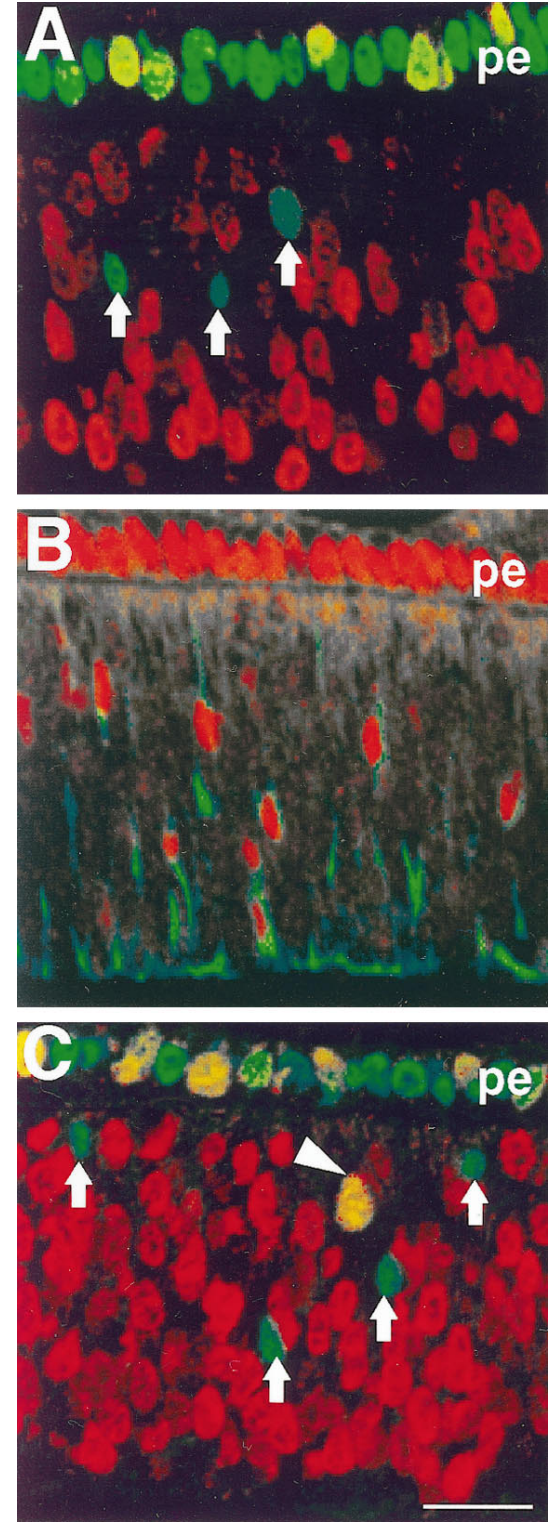

Figure 4. OTX2 is expressed in postmitotic retinal neuroblasts. Confocal microscopic images of frontal cryostat sections of E4 chick retinas fixed 3 $(A, B)$ or $8 \mathrm{hr}$ after BrdU administration $(C)$, immunostained with antiserum against OTX2 (green in $A, C$; red in $B$ ), and double stained with a $\mathrm{mAb}$ directed against $\mathrm{BrdU}$ (red in $A, C$ ) or with the $3 \mathrm{~A} 10 \mathrm{mAb}$ (green in $B$ ). OTX2-positive cells (arrows) localized in the inner third of the retina are not stained with anti-BrdU mAb $3 \mathrm{hr}$ after $\operatorname{BrdU}$ administration $(A)$. In contrast, all OTX2-positive cells express in their cytoplasm the 3A10 antigen $(B)$. The first OTX2 and BrdU double-stained cells (orange, arrowhead) are first visible $8 \mathrm{hr}$ after BrdU administration $(C)$.pe, Pigment epithelium. Scale bar, $30 \mu \mathrm{m}$.

neuroepithelium $3 \mathrm{hr}$ after BrdU administration, suggesting that BrdU-positive cells were between the $S$ and $G_{2}$ phases. However, no BrdU staining co-localized with the signal for OTX2, present in the nuclei of the inner third of the retina (Fig. 4A). Instead, OTX2-positive cells were all stained with 3A10, a mAb directed against a neurofilament associated protein expressed by neurons (Fig. 4B) (Furley et al., 1990). This indicates that OTX2 was expressed by cells committed to a neuronal fate that had undergone their last mitosis before BrdU administration. To determine how much time elapses between DNA replication and OTX2 expression, embryos were fixed and analyzed $4-12 \mathrm{hr}$ after injec- tion. OTX2 and BrdU double-stained cells were first observed in embryos fixed at $8 \mathrm{hr}$ after injection (Fig. $4 C$ ). Because cells of E3-E5 (HH20-HH27) chick retinas undergo their last mitosis approximately $6 \mathrm{hr}$ after DNA replication (Waid and McLoon, 1995), it could be concluded that neural retina cells express OTX2 a few hours after terminal mitosis.

\section{OTX2 is expressed during the differentiation of distinct cell classes}

Given that Otx2 is expressed only in retinal cells already committed to a neuronal fate, we set out to determine whether Otx2 expression in the retina was limited to a particular cell type or was generally expressed by all cells leaving the mitotic cycle, independent of their final identity.

The order of cell type generation is conserved in vertebrate retinas (Altshuler et al., 1991). RGCs are always generated first, followed by horizontal, photoreceptor, and amacrine cells, whereas bipolar and Müller cells are born in the last period of neurogenesis. At E3.5 (HH22), basically only RGCs have begun to leave the mitotic cycle in the chick retina. Their differentiation is quite fast, and by E5 (HH27) about half of the RGCs are born, following a centroperipheral, dorsoventral, and temporonasal gradient, as for all other cell types (Prada et al., 1991). Thus, at $\mathrm{HH} 22$, the most likely identity of OTX2-positive, postmitotic neuroblasts was that of differentiating RGCs. To test this assumption, E3.5 and E5 retinas were double labeled with anti-OTX2 antiserum and RA4, a mAb that specifically recognizes postmitotic and premigratory RGCs soon after their last division (McLoon and Barnes, 1989; Waid and McLoon, 1995). At E3.5, the great majority of OTX2-positive cells were double stained with RA4 (Fig. 5A). In 10 different E3.5 retinas, the average number of double-labeled cells was $10 \pm 2$ per section, almost coincident with the number calculated for OTX2 and 3A10 double-labeled cells $(11 \pm 3)$. At E5 the number of OTX2- and RA4-positive cells increased (Fig. $5 C$ ), occupying both the central and peripheral region of the retina $(56 \pm 15$ per section in the central portion). At this stage a few OTX2-positive, single-labeled cells were also observed, and their number together with that of differentiating RGCs closely matched the number estimated for OTX2- and 3A10-positive cells $(69 \pm 13$ per section in the central portion). Once in their final position, RGCs, identified with a mAb directed against islet-1 (Fig. 5B,D) (Austin et al., 1995), never stained with anti-OTX2 antiserum (Fig. 5B,D). Taken together, these data clearly indicate that OTX2 is expressed in RGCs; however, it is expressed in a transient manner, being present during the migration from the mitotic to the mantle layer of the retina.

The number of cells that expressed OTX2 but not the RGCspecific marker RA4 was higher at E5 than at E3.5, as expected if OTX2 expression was associated with cell classes other than RGCs. In agreement with this idea, many OTX2- and 3A10positive cells were still present in E7 (HH31) central retinas (Fig. $5 E$ ), where OTX2- and RA4-positive cells could no longer be observed. This staining pattern coincides with the bulk of horizontal, photoreceptor, and amacrine cell generation (Prada et al., 1991).

The retinal neuroepithelium gives rise not only to six different types of neurons but also to a specialized kind of glial cell, the Müller cell. If OTX2 expression was a common feature in the differentiation of retina neuroepithelial cells, then it should be anticipated that Müller cells also express OTX2. 3CB2 is a mAb directed against an intermediate filament-related antigen, which selectively labels Müller 

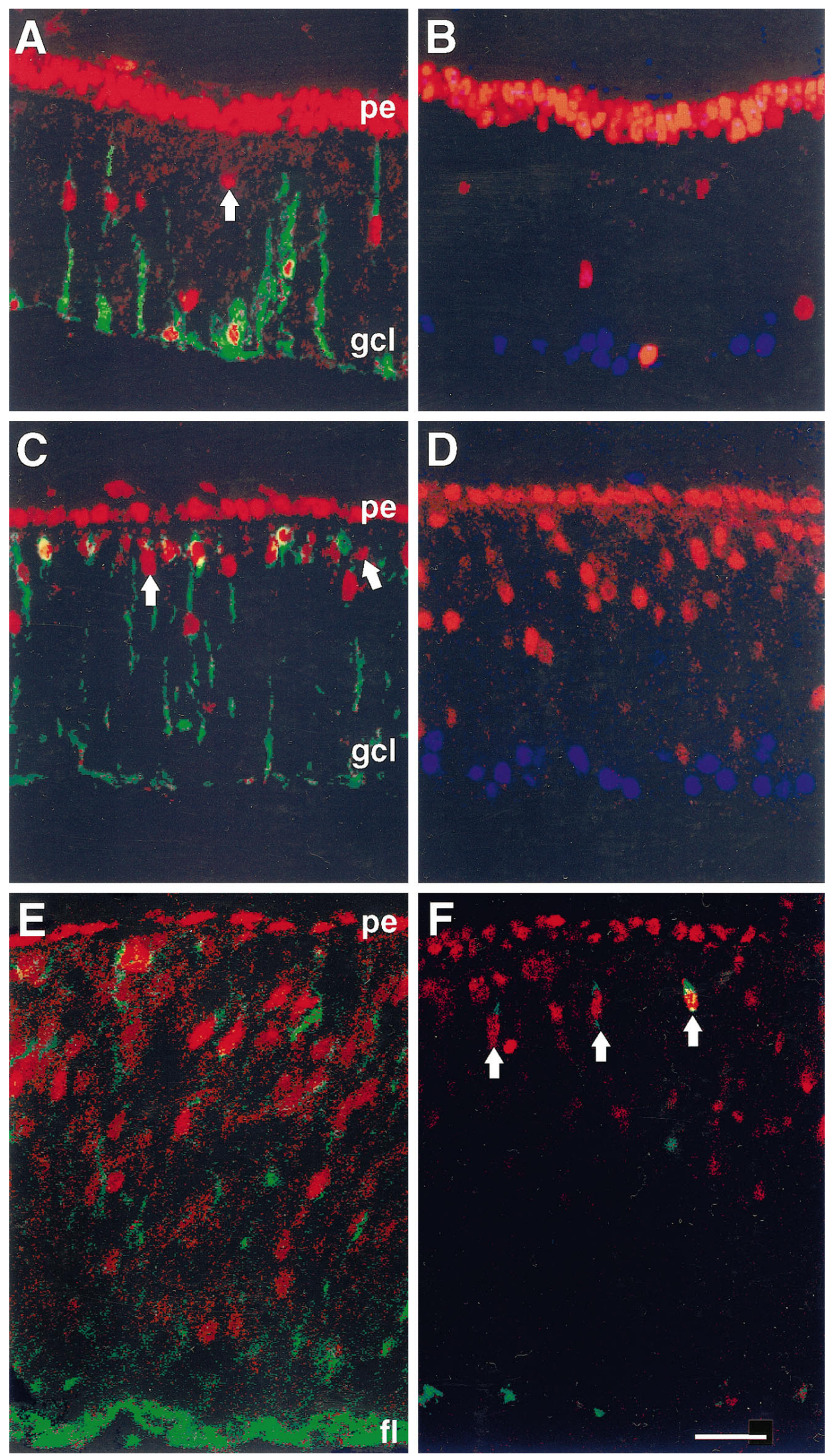

Figure 5. OTX2 is transiently expressed by differentiating RGCs and by cells differentiating into phenotypes other than RGCs. Confocal microscopic images of frontal cryostat sections of chick retinas immunostained with antiserum against OTX2 (red) at E3 $(A, B)$, E5 $(C, D)$, and E7 $(E, F)$ double stained with the RA4 mAb (green in $A, C$ ), the anti-islet-1 $\mathrm{mAb}($ blue in $B, D)$, the $3 \mathrm{~A} 10 \mathrm{mAb}$ (green in $E$ ), or the $3 \mathrm{CB} 2 \mathrm{mAb}$ (green in $F$ ). The majority of OTX2-positive cells could be identified as RGCs with the RA4 mAb; only a few cells (arrows) were stained only for OTX2 $(A$, $C)$. Islet-1-positive RGCs in the mantle do not express OTX2 $(C, D)$. At E7 the majority of OTX2-positive cells are neurons expressing the 3A10 antigen $(E)$. A few OTX2-positive cells can be identified as Müller cells (arrows) by their expression of the $3 \mathrm{CB} 2$ antigen $(F)$. $f l$, Fiber layer; $g c l$, ganglion cell layer; $p e$, pigment epithelium. Scale bar, $A-D, 30 \mu \mathrm{m}$; $E, F, 20 \mu \mathrm{m}$.

cells as they leave the cell cycle at E7 (Prada et al., 1995). Thus, E7 chick retinas were double stained with anti- OTX2 and -3CB2. At this stage, a few cells, identified as developing Müller cells by 3CB2 staining, were also labeled with anti OTX2 (Fig. 5F), providing evidence that both neuronal and glial cell types in the chick retina express OTX2 during the course of their differentiation. 


\section{DISCUSSION}

In this study we have analyzed the expression pattern of Otx2 mRNA and protein during chick eye formation. Otx 2 demarcates a dorsal domain within the eye primordium from which the pigment epithelium derives. This is a novel finding, which supports the idea of a boundary between the dorsal and the ventral eye domains (Jacobson, 1983). Otx2 expression in the prospective pigment epithelium is complementary to that of $\operatorname{Pax} 2$, the expression of which is first confined to the ventral portion of the eye and is thereafter restricted to the optic stalk. Furthermore, Otx 2 expression was observed in the neural retina at the beginning of cell differentiation, associated with postmitotic neuroblasts committed to both neuronal and glial cell types. OTX2 was present only transiently during RGC differentiation but persisted up to complete maturation in other cell classes. Together these data suggest that $O t x 2$ might have a double role in eye development, first in the early specification and later function of the pigment epithelium and second in retinal neurogenesis.

\section{Otx2 expression at early stages of eye development}

In vertebrates the region from which the eye originates is located within the most anterior portion of the neural plate together with those of other anterior structures (i.e., olfactory placodes, neurohypophysis, hypothalamus, and ventral forebrain; Couly and Le Douarin, 1988). Transcription regulators known to be important in eye development, such as Pax6 and Six3, and Otx2 itself are expressed throughout the anterior neural plate, although with different posterior boundaries (Walther and Gruss, 1991; BallyCuif et al., 1995; Oliver et al., 1995; Bovolenta et al., 1996a). Thus, so far, there has been no description of a gene that clearly identifies only "eye-fated" cells. Nevertheless, it has been established that Pax 6 and probably Six3 play a general and fundamental role in eye morphogenesis, because they are widely expressed in the different tissues involved in this process (Grindley et al., 1995; Halder et al., 1995; Oliver et al., 1995; Bovolenta et al., 1996a). The results of this paper show that the role of $O t x 2$ during eye morphogenesis might be more specific, defining the pigment epithelium. This is suggested by its restricted expression first in the dorsal portion of the optic vesicles and afterward in the outer layer of the optic cup, with a clear boundary at the optic stalk, where Pax2 is expressed. To date, Otx2 is the first homeoboxcontaining gene known to be persistently expressed in the pigment epithelium. Other genes are either transiently expressed (Pax6; Walther and Gruss, 1991) or totally absent from both the prospective and the definitive pigment epithelium (Six-3; P. Bovolenta, unpublished observations). How Otx2 expression is restricted to the dorsal part of the optic vesicle is a matter of speculation. However, it is interesting to note that $O t \times 2$ disappears from the distal edge of the vesicle soon after its contact with the surface ectoderm, suggesting a possible causative interaction. Furthermore, Otx 2 expression seemed limited by that of Pax2. A clear border exists between the expression domain of the two genes, and it is possible that a reciprocal control might exist. In this respect, in Pax2 null mutant mice, pigmentation, which normally stops at the Pax2-expressing cells of the optic stalk, is extended along the optic stalk (Torres et al., 1996).

The presence of the pigment epithelium is fundamental for eye morphogenesis and function (Bok, 1993; Raymond and Jackson, 1995). In fact, diffusible factors, such as neurotrophin-3 and IGF-I, known to promote neural retina differentiation in vivo, are synthesized in the pigment epithelium from which they diffuse into the neuroepithelium (Bovolenta et al., 1996b; Frade et al.,
1996). Whether Otx2 is only needed to determine and maintain pigment epithelium fate or whether it is also necessary for its functions is currently under study.

\section{OTX2 expression in the developing neural retina and its implication in cell differentiation}

In the developing neural retina, OTX2 was expressed by postmitotic neuroblasts of both neuronal and glial lineage. Chick embryos of different ages were exposed to BrdU for the time necessary for a retinal neuroepithelial cell to go from the $\mathrm{S}$ to the $\mathrm{M}$ phase of the cell cycle (Waid and McLoon, 1995). During this time there was no co-localization between OTX2 immunoreactivity and BrdU incorporation. Instead OTX2 expression was coincident with that of a neurofilament-associated antigen (recognized by the $3 \mathrm{~A} 10 \mathrm{mAb}$ ), present in differentiating neurons. This clearly demonstrated that the onset of OTX2 expression in retinal cells was postmitotic. Thus, OTX2 expression in the neural retina differs from that in other regions of the vertebrate CNS, where its spatiotemporal distribution suggests an association with proliferating neuroblasts (Simeone et al., 1992, 1993), with the exception of the rat cerebellum and mouse superior colliculus, in which Otx2 has been detected both in proliferating and in postmitotic cells (Frantz et al., 1994; Mallamaci et al., 1996).

Furthermore, we provide a detailed analysis of the correlation between OTX2 expression and the differentiation of retinal ganglion cells. Using two RGC-specific markers, we demonstrate that OTX2 is transiently expressed in RGCs. Indeed, at the time when only RGCs are generated, basically all OTX2-positive cells were double stained with the RA4 mAb. OTX2- and RA4-positive RGCs were observed at different stages of their migration. However, RGCs in the mantle layer, recognized by their expression of islet-1, suppress OTX2 expression, and Otx2 products were never observed in mature RGCs.

Such a detailed analysis could not be performed for all neuron cell classes, because no early and specific markers are available for chick retinal interneurons or photoreceptors. Nevertheless, we demonstrate that cells committed to a neuronal fate, distinct from that of RGCs, expressed OTX2. Thus, at E7, when almost all RGCs have been born in the chick central retina (Prada et al., 1991), the majority of OTX2-positive cells were double labeled with a neuron-specific marker (3A10 mAb). The idea that different retinal cell types expressed OTX 2 was further supported by the late detection of OTX2 in layered horizontal and photoreceptor cells. In addition, we proved that glial cells, the Müller cells, also expressed OTX2 at the time of their generation. These data allowed us to postulate, as schematized in Figure 6, that OTX2 expression may define a common differentiation feature of all postmitotic retina cell types.

Several of the steps involved in retinal neurogenesis have been established. The generation of cell types from the retina neuroepithelium occurs in a precise time sequence, each cell type of an adult retina being generated only in a particular period of development (Altshuler et al., 1991). However, lineage analysis has shown that a single early retinal precursor cell can give rise to all the retinal cell types (Holt et al., 1988; Wetts and Fraser, 1988, Turner et al., 1990). This toti potency may become restricted with time, and early differentiating cell types may inhibit uncommitted cells from differentiating into the same cell type, or early generated cell types may actively induce the generation of later phenotypes. Indeed, neurogenic genes, such as Notch or Delta, (Austin et al., 1995; Dorsky et al., 1995, 1997), and several helix-loophelix transcription factors (Ferreiro et al., 1993; Guillemot and 
PE

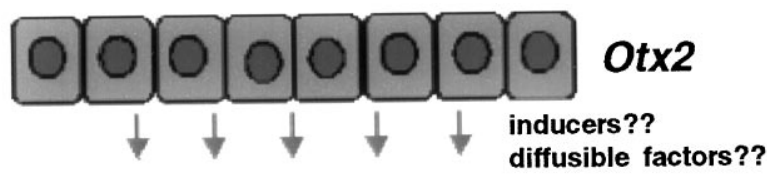

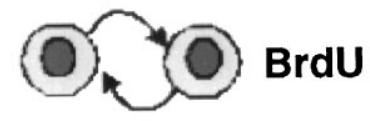
cells

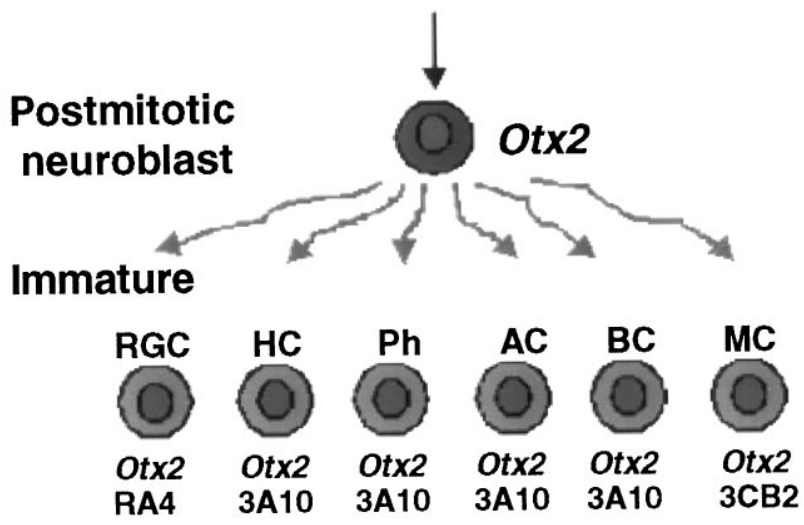

Figure 6. Summary diagram of OTX2 expression during neural retina differentiation. During retinal neurogenesis the pigment epithelium may provide signals (inducers??, diffusible factors??) necessary for the differentiation of the retina. Retinal neuroblasts may all express Otx2 as a common feature of their differentiation. However, although some cell types, e.g., RGCs and amacrine cells $(A C)$, lose $O t x 2$ expression after their final maturation, other cell types, e.g., photoreceptors $(P h)$ and Müller cells $(M C)$, continue to express it. $H C$, Horizontal cells; $B C$, bipolar cells.

Joyner, 1993; Tomita et al., 1996) are expressed in progenitor cells and seem to control cell fate and the process of phenotypic restriction during retinal neurogenesis. An additional problem is to establish when a given cell becomes committed to a specific phenotype. There is evidence suggesting that cell commitment occurs during or right after the last cell division (Waid and McLoon, 1995) and that commitment can take place even in the absence of mitosis (Harris and Hartenstein, 1991).

This paper shows that OTX2 is probably expressed in retinal cells a few hours after their last cell division, at the beginning of their differentiation. How OTX2 expression fits into the general scheme of retinal neurogenesis is an open question. Otx 2 could be involved in stabilizing the cells in their postmitotic state and/or may allow all retinal cells, independent of their final fate, to be receptive to differentiation signals present, at any given time, in the surrounding environment. The availability of a given factor(s) would be the ultimate determinant of the cell phenotype. Should

this be the case, postmitotic OTX2-positive cells might have the potential of generating all different cell types. Thus, modifying the signals available at given times in retinal development should enable the ordered fate of OTX2-positive postmitotic cells to be altered without, however, changing the overall number of OTX2positive cells at any given time. Appropriate experiments are needed to demonstrate this idea. It is worth noting, however, that the overexpression of the epidermal growth factor receptor in rat retinas, a potential signal for the differentiation of retinal neuroepithelial cells, resulted in a premature and enhanced differentiation of Müller cells (Lillien, 1995).

As an alternative hypothesis, Otx2 could be involved in the process of cell movement, as has been proposed with respect to its expression in the mouse olfactory system (Mallamaci et al., 1996). This idea is supported by the transient expression of OTX2 in the $\mathrm{RGC}$, expression that is coincident with the cell migration from the ventricular to the mantle layer. In this case, OTX2 should have an additional or different role in, for instance, layered horizontal or photoreceptor cells. Independent of its function, however, the data reported here demonstrate that OTX2 might be, at least, a useful tool to study further the steps necessary to generate retinal cell diversity.

\section{REFERENCES}

Acampora D, Mazan S, Lallemand Y, Avantaggiato V, Maury M, Simeone A, Brûlet P (1995) Forebrain and midbrain regions are deleted in Otx2-/- mutants due to a defective anterior neuroectoderm specification during gastrulation. Development (Camb) 121:3279-3290.

Altshuler D, Turner DL, Cepko CL (1991) Specification of cell types in the vertebrate retina. In: Development of the visual system: proceeding of the retina research foundation symposia (Lam DMK, Shatz CJ, eds), pp 37-58. Cambridge, MA: MIT.

Ang SL, Jin O, Rhinn M, Daigle N, Stevenson L, Rossant J (1996) A targeted mouse Otx2 mutation leads to severe defects in gastrulation and formation of axial mesoderm and to deletion of rostral brain. Development (Camb) 122:243-252.

Austin CP, Feldman DE, Ida JA, Cepko C (1995) Vertebrate RGCs are selected from competent progenitors by the action of Notch. Development (Camb) 121:3637-3650.

Bally-Cuif L, Gulisano M, Broccoli V, Boncinelli E (1995) c-otx-2 is expressed in two different phases of gastrulation and is sensitive to retinoic acid treatment in chick embryo. Mech Dev 49:49-63.

Bok D (1993) The retinal pigment epithelium: a versatile partner in vision. J Cell Sci Suppl 17:189-195.

Boncinelli E, Mallamaci A (1995) Homeobox genes in vertebrate gastrulation. Curr Opin Genet Dev 5:619-628.

Bovolenta P, Mallamaci A, Boncinelli E (1996a) Cloning and characterization of two chick homeobox genes, members of the Six/sine oculis family, expressed during eye development. Int J Dev Biol [Suppl] 1:73-74.

Bovolenta P, Frade JM, Marti E, Rodriguez-Peña MA, Barde YA, Rodriguez-Tebar A (1996b) Neurotrophin-3 antibodies disrupt the normal development of the chick retina. J Neurosci 16:4402-4410.

Couly G, Le Douarin NM (1988) The fate map of the cephalic neural primordium at the presomitic to the 3 -somite stage in the avian embryo. Development (Camb) [Suppl] 103:101-113.

Dorsky RI, Rapaport DH, Harris WA (1995) Xnotch inhibits cell differentiation in the Xenopus retina. Neuron 14:487-496.

Dorsky RI, Chang WS, Rapaport DH, Harris WA (1997) Regulation of neuronal diversity in the Xenopus retina by Delta signaling. Nature 385:67-70.

Ferreiro B, Skoglung A, Bailey R, Dorsky RI, Harris WA (1993) XASH-1, a Xenopus homolog of achaete-scute: a proneural gene in anterior region of the CNS. Mech Dev 40:25-36.

Finkelstein R, Perrimon N (1991) The molecular genetics of head development in Drosophila melanogaster. Development (Camb) 112:899-912.

Frade JM, Marti E, Bovolenta P, Rodriguez-Peña MA, Perez-Garcia D, Rohrer H, Edgar E, Rodriguez-Tebar A (1996) Insulin-like growth factor-1 governs neuron differentiation in the developing chick retina both in vitro and in vivo. Development (Camb) 122:2497-2506. 
Frantz G, Weimann JM, Levin ME, McConnell SK (1994) Otx1 and Otx2 define layers and regions in developing cerebral cortex and cerebellum. J Neurosci 14:5725-5740.

Furley AJ, Morton SB, Manalo D, Karagogeos D, Dodd J, Jessell TM (1990) The axonal glycoprotein TAG-1 is an immunoglobulin superfamily member with neurite outgrowth promoting activity. Cell 61:157-170.

Gehring WJ, Quian YQ, Billeter M, Furokubo-Tokonaga K, Schier AF, Resendez-Perez D, Affolter M, Otting G, Würthrich K (1994) Homeodomain-DNA recognition. Cell 78:211-223.

Grindly JC, Davison DR, Hill RE (1995) The role of pax-6 in eye and nasal development. Development (Camb) 121:1433-1442.

Guillemot F, Joyner AL (1993) Dynamic expression of the murine achaete-scute homolog (Mash-1) in the developing nervous system. Mech Dev 42:171-185.

Halder G, Callaerts P, Gehring WJ (1995) New perspective on eye development. Curr Opin Genet Dev 5:602-609.

Hamburger V, Hamilton H (1951) A series of normal stages in the development of chick embryo. J Morphol 88:49-92.

Harris WA, Hartenstein V (1991) Neuronal determination without cell division in Xenopus embryos. Neuron 6:499-515.

Holt CE, Bertsch TW, Ellis HM, Harris WA (1988) Cellular determination in the Xenopus retina is independent of lineage and birth date. Neuron 1:15-26.

Jacobson M (1983) Clonal organization of the CNS of the frog. J Neurosci 3:1019-1038.

Khan AJ (1973) Ganglion cell formation in the chick neural retina. Brain Res 63:285-290.

Lawrence PA, Morata G (1994) Homeobox genes: their function in Drosophila segmentation and pattern formation. Cell 78:181-189.

Lillien L (1994) Neurogenesis in the vertebrate retina. Perspect Dev Neurobiol 2:175-182.

Lillien L (1995) Changes in retinal cell fate induced by overexpression of EGF receptor. Nature 377:158-162.

Macdonald R, Barth KA, Xu Q, Holder N, Mikkola I, Wilson-SW (1995) Midline signalling is required for Pax gene regulation and patterning of the eyes. Development (Camb) 121:3267-78.

Mallamaci A, Di Blas E, Briata P, Boncinelli E, Corte G (1996) OTX2 homeoprotein in the developing central nervous system and migratory cells of the olfactory area. Mech Dev 58:165-178.

Matsuo I, Kuratani S, Kimura C, Takeda N, Aizawa S (1995) Mouse Otx2 functions in the formation and patterning of rostral head. Genes Dev 9:2646-2658.

McLoon SC, Barnes RB (1989) Early differentiation of RGCs: an axonal protein expressed by premigratory and migrating RGCs. J Neurosci 9:1424-1432.

Nieto MA, Patel K, Wilkinson DG (1996) In situ hybridization analysis of chick embryos in whole mount and tissue sections. Methods Cell Biol $51: 219-235$

Nornes HO, Dressler GR, Knapik EW, Deutsch U, Gruss P (1990)
Spatially and temporally restricted expression of Pax2 during murine neurogenesis. Development (Camb) 109:797-809.

Oliver G, Mailhos A, Wehr R, Copeland NG, Jenkins NA, Gruss P (1995) Six3, a murine homologue of the sine oculis gene, demarcates the most anterior border of the developing neural plate and is expressed during eye development. Development (Camb) 121:4045-4055.

Prada C, Puga J, Lòpez-Mèndez L, Lòpez R, Ramìrez G (1991) Spatial and temporal patterns of neurogenesis in the chick retina. Eur J Neurosci 3:559-569.

Prada FA, Dorado ME, Quesada A, Prada C, Schwartz U, De La Rosa E (1995) Early expression of a novel radial glia antigen in the chick embryo. Glia 15:389-400.

Puschel AW, Westerfield M, Dressler GR (1992) Comparative analysis of Pax-2 protein distributions during neurulation in mice and zebrafish Mech Dev 38:197-208.

Raymond SM, Jackson IJ (1995) The retinal pigment epithelium is required for the development and maintenance of the mouse neural retina. Curr Biol 5:1286-1295.

Saha MS, Servetnick M, Grainger RM (1992) Vertebrate eye development. Curr Opin Genet Dev 2:582-588.

Schaeren-Wiemers N, Gerfin-Moser A (1993) A single protocol to detect transcripts of various types and expression levels in neural tissue and cultured cells: in situ hybridization using digoxigenin-labeled cRNA probes. Histochemistry 100:431-440.

Simeone A, Acampora D, Gulisano M, Stornaiuolo A, Boncinelli E (1992) Nested expression domains of four homeobox genes in the developing rostral brain. Nature 358:687-690.

Simeone A, Acampora D, Mallamaci A, Stornaiuolo A, D’Apice MR, Nigro V, Boncinelli E (1993) A vertebrate gene related to orthodenticle contains a homeodomain of the bicoid class and demarcates anterior neuroectoderm in the gastrulating mouse embryo. EMBO J 12:2735-2747.

Tomita K, Ishibashi M, Nakahara K, Ang SL, Nakanishi S, Guillemot F, Kageyama R (1996) Mammalian hairy and enhancer of Split homolog 1 regulates differentiation of retinal neurons and is essential for eye morphogenesis. Neuron 16:723-734.

Torres M, Gomez-Pardo E, Gruss P (1996) Pax2 contributes to inner ear patterning and optic nerve trajectory. Development (Camb) 122:3409-3418.

Turner DL, Snyder EY, Cepko CL (1990) A common progenitor for neurons and glia persists in rat retina late in development. Nature 328:131-136.

Waid DK, McLoon SC (1995) Immediate differentiation of ganglion cells following mitosis in the developing retina. Neuron 14:117-124.

Walther C, Gruss P (1991) Pax-6, a murine paired box gene, is expressed in the developing CNS. Development (Camb) 113:1435-1449.

Wetts R, Fraser SE (1988) Multipotent precursors can give rise to all major cell types of the frog retina. Science 239:1142-1145.

Young RW (1985) Cell differentiation in the retina of the mouse. Anat Rec 212:199-205. 